\title{
COVID-19 Pandemic and Domestic Violence Against Women: Implications of Strategies to Protect Women
}

\author{
Marzieh Azizi $\mathbb{D}^{1}{ }^{1}$, Zahra Behboodi Moghadam (iD) ${ }^{2}$, Mohsen Aarabi ${ }^{3}$ and Forouzan Elyasi ${ }^{4}{ }^{4,5},{ }^{*}$ \\ ${ }^{1}$ School of Nursing and Midwifery, Tehran University of Medical Sciences, Tehran, Iran \\ ${ }^{2}$ Department of Reproductive Health and Midwifery, School of Nursing and Midwifery, Tehran University of Medical Sciences, Tehran, Iran \\ ${ }^{3}$ Department of Family Medicine, School of Medicine, Mazandaran University of Medical Sciences, Sari, Iran \\ ${ }^{4}$ Psychiatry and Behavioral Sciences Research Center, Sexual and Reproductive Health Research Center, Addiction Institute, Mazandaran University of Medical Sciences, Sari, \\ Iran \\ ${ }^{5}$ Department of Psychiatry, School of Medicine, Mazandaran University of Medical Sciences, Sari, Iran \\ "Corresponding author: Psychosomatic Ward, Imam Khomeini General Hospital, Sari, Mazandaran, Iran. Tel: +98-1133370885, Fax: +98-1133363754, Emails: \\ forouzan.elyasi@gmail.com; f.elyasi@mazums.ac.ir
}

Received 2021 January 03; Revised 2021 January 19; Accepted 2021 February 23.

Keywords: COVID-19, Domestic Violence, Pandemic, Strategies

\section{Dear editor,}

Domestic violence (DV) is one of the most common forms of violence against women worldwide (1). Literature indicated that approximately 1 in 3 women across the world has been exposed to intimate partner violence (2). Associated factors of spousal DV against women in developing societies include gender inequality, the dominance of a patriarchal view, a cultural acceptance of abuse against women, and a property-oriented view toward women and children (3).

The COVID-19 has broad impacts on physical and mental health and also negative social consequences (4). During the COVID-19 pandemic, local government officials have published guidelines about the importance of staying at home and follow quarantine in order to protect themselves and the community $(1,5,6)$. Factors such as social isolation, the closure of many schools, imposing travel restrictions, unemployment, and financial strains lead to considerable psychological distress, DV, and overall more negative effect on family's well-being and relationship (1, 79 ). Based on the literature, the unpredictable condition of the current pandemic increased the marital incompatibility and also the possibility of DV(7). According to the World Health Organization, reporting on DV against women remain scarce; however, statistical reports of countries such as China, the United Kingdom, the United States, and other countries suggest an increase in cases of DV since the emergence of COVID-19 (10) so that 30\% increase in DV reports in France, 40 - 50 \% in Brazil and also increased the rates in countries such as Italy, Spain, and Iran $(2,7)$. As the pandemic may continue, the attention to the DV issue and the need for advocating women under violence to prevent the possibility of reoccurrence of the violence by considering strategic plans and improving community collaborations in this problem is a key action to ensure public safety during the pandemic (5).

Literature review showed that although various studies performed regarding DV during COVID-19 pandemic (1113), there is no study that assessed the best strategy against DV. In some published articles during the pandemic, we extracted some strategies for preventing and managing DV among women. In this study, strategies were classified into two main categories, including preventive strategies and assistant or supportive strategies. Programs for victims of DV are an integral part of the community approaches to prevent violence (14). Preventive strategies aimed to prevent the occurrence of DV against women through primary prevention methods in women likely exposed to a higher risk of violence (1). Preventive strategies such as increased public awareness through the media and social networks about the possibility of increased domestic or increased psychological consequences, leading to violence for a variety of reasons during the critical period of the COVID-19 pandemic, are considerably important (2). Stabilization of social norms that makes the occurrence of DV unacceptable is the first social effort in controlling the DV during the COVID-19 pandemic (10). Also, to decrease the prevalence of $\mathrm{DV}$, educating anger management to women and to their husbands and also empowering women to self-care is essential planning (2). Another strategy to prevent DV is to inform and educate men about changing their attitudes toward women's and girl's rights, accept their equal rights 
in all life aspects, to aware of legal consequences of this rough behavior as well as train life skills to prevent violence against women to couples (4). Moreover, providing social services about violence during the pandemic and creating social works and guidance units in family courts efficiently for abused women can be appropriate planning for women in high-risk regions to prevent DV and increase women's health in multifaceted dimensions (15).

In addition to a variety of preventive and educational services at the community level, DV agencies typically provide some combination of the following services with victims of DV who are categorized into assistant or supportive strategies such as establishing crisis hotlines, strengthening and developing social crisis intervention centers, establishing safe places, and emergency shelters for women vulnerable to DV during COVID-19 $(4,14,16)$. Supporting healthcare and social service agencies in offering virtual counsel and telemedicine options include a telephone crisis hotline 24 hours a day, 7 days a week (4).

Addressing DV requires a careful combination of legal actions, societal responses such as advocacy services, shelters, and heightened awareness in community healthcare services such as physicians who are responsible for the assessment of victims with physical or psychological trauma, sexually transmitted infections, neglect, or other types of abuse. Mental health and psychology services can play a key role in addressing this issue through addressing certain risk factors for perpetration of DV, providing social and psychological support, advocacy and treatment services for victims of DV, and multi-agency working to strengthen medical and social responses to DV (9).

Shelters are a critical feature of services for abused women and their children, providing time for women to think about their options and begin to reconstruct their personal life with social, legal, and medical assistance if needed (14). In Iran, information is provided through the media about the launch of social emergencies to support women who have been physically and emotionally abused during the pandemic by dialing 123 number (17). Another strategy is to establish and strengthen active nongovernmental organizations (NGOs) in the field of combating DV with the aim of supporting victims and forming public networks, including mosques, cultural, counseling, and charitable organizations, to support and provide assistance services for victims (18). Overall, communities should ensure their citizens are aware of the increased risk of DV during the pandemic and encourage them to report any concerns they have experienced in their marital relationships (7).

Empowering physicians and healthcare workers to manage cases of DV and integrate services related to DV in the primary healthcare system, and providing a refer- ral for women victims of violence in the healthcare system are other important actions for DV during the pandemic. Altogether, because of the complexity of DV, a system-wide response, both through local healthcare systems and the larger community system, should be considered for women under violence. Healthcare professionals clearly can play a significant role in the DV against women by simply violence screening and offering help and referral (8). Early detection and intervention can reduce disease, injury, and death related to DV against women (19). Implementing psychological non-pharmacological interventions such as group counseling therapy and family therapy with a focus on education and empowerment of vulnerable women are investigated in some studies $(14,20)$. Studies that investigated the efficacy of counseling for women under DV showed psychoeducational, supportive counseling for abused women might be an effective approach for improving women's self-esteem, assertiveness, social support, coping abilities, and self-efficacy $(14,20,21)$. Also, a study showed that innovative crisis counseling support services such as encourage contacting counselors to talk about their stress and concerns can be provided to women during the pandemic due to social isolation and distancing (22).

Notably, substance use disorders, as principal or comorbid diagnoses, harbor the highest absolute and relative risks of domestic violence, so treatment of these disorders, alongside any co-existing mental illness, should be prioritized to possibly reduce risk (23).

Setting up a national database collaboration between government and civil society organizations can be recommended to register the reported cases of violence. Organizations in the UK have called for special police powers to help DV survivors. Also, in Italy, a trade union group has demanded that the perpetrator of violence should be made to stay in a shelter during the pandemic. In Greece, police forces are investing in the public population to increase their awareness about DV during the pandemic and educating strategies that will assist survivors in seeking help (24). The Scottish government has assigned considerable grants for organizations working to help survivors of abuse and rape to ensure that abused women access to supportive services during the COVID outbreak (23). Overall, these strategies should have a positive effect on women's attitude toward reporting any type of violence experienced not only during the pandemic but also in their life span, and the main outcome will be women's empowerment in their marital relationships (2).

Given that the possibility of DV during the pandemic is increased all over the world, providing appropriate cultural-based strategies to women is an important issue to increase their ability for self-care during this pandemic 
and improve their physical and psychological health status.

\section{Footnotes}

Authors' Contribution: Marzieh Azizi and Forouzan Elyasi designed and conducted the study and wrote the initial draft. Zahra Behboodi Moghadam and Mohsen Aarabi edited the final manuscript and provided critical revision for important intellectual content. All authors read and approved the final manuscript.

Conflict of Interests: The authors declare that they have no competing interests.

Funding/Support: There is no funding/support.

\section{References}

1. Rauhaus BM, Sibila D, Johnson AF. Addressing the increase of domestic violence and abuse during the covid-19 pandemic: A need for empathy, care, and social equity in collaborative planning and responses. Am Rev Public Adm. 2020;50(6-7):668-74. doi: 10.1177/0275074020942079.

2. Sharifi F, Larki M, Latifnejad Roudsari R. COVID-19 outbreak as threat of violence against women. JMRH. 2020;8(3):2376-9.

3. Ozaki R, Otis MD. Gender equality, patriarchal cultural norms, and perpetration of intimate partner violence: Comparison of male university students in Asian and European cultural contexts. Violence Against Women. 2017;23(9):1076-99. doi: 10.1177/1077801216654575. [PubMed: 27378719].

4. Viveiros N, Bonomi AE. Novel coronavirus (COVID-19): Violence, reproductive rights and related health risks for women, opportunities for practice innovation. J Fam Violence. 2020;11:1-5. doi: 10.1007/s10896020-00169-x. [PubMed: 32836735]. [PubMed Central: PMC7275128].

5. Kofman YB, Garfin DR. Home is not always a haven: The domestic violence crisis amid the COVID-19 pandemic. Psychol Trauma. 2020;12(1):S199-201. doi: 10.1037/tra0000866. [PubMed: 32478558]. [PubMed Central: PMC7720288].

6. Bullinger LR, Carr J, Packham A. COVID-19 and crime: Effects of stay-athome orders on domestic violence. NBER; 2020. Available from: https: //www.nber.org/papers/w27667.

7. Campbell AM. An increasing risk of family violence during the Covid19 pandemic: Strengthening community collaborations to save lives. Forensic Sci Int. 2020;2:100089. doi:10.1016/j.fsir.2020.100089.

8. Matoori S, Khurana B, Balcom MC, Koh DM, Froehlich JM, Janssen S, et al. Intimate partner violence crisis in the COVID-19 pandemic: how can radiologists make a difference? Eur Radiol. 2020;30(12):6933-6. doi: 10.1007/s00330-020-07043-w. [PubMed: 32607631]. [PubMed Central: PMC7326304].

9. Gulati G, Kelly BD. Domestic violence against women and the COVID19 pandemic: What is the role of psychiatry? Int J Law Psychiatry. 2020;71:101594. doi: 10.1016/j.ijlp.2020.101594. [PubMed: 32768101]. [PubMed Central: PMC7264022].
10. WHO. COVID-19 and violence against women: what the health sector/system can do. 2020, [cited 7 April 2020]. Available from: https: //apps.who.int/iris/handle/10665/331699.

11. Hatchimonji JS, Swendiman RA, Seamon MJ, Nance ML. Trauma does not quarantine: Violence during the COVID-19 PANDEMIC. Ann Surg. 2020;272(2):e53-4. doi: 10.1097/SLA.0000000000003996. [PubMed: 32675495]. [PubMed Central: PMC7224619].

12. Piquero AR, Riddell JR, Bishopp SA, Narvey C, Reid JA, Piquero NL. Staying home, staying safe? A short-term analysis of COVID-19 on dallas domestic violence. Am J Crim Justice. 2020;14:1-35. doi: 10.1007/s12103020-09531-7. [PubMed: 32837161]. [PubMed Central: PMC7293590].

13. Mahase E. Covid-19: EU states report $60 \%$ rise in emergency calls about domestic violence. BMJ. 2020;369:m1872. doi: 10.1136/bmj.m1872. [PubMed: 32393463].

14. Bennett L, Riger S, Schewe P, Howard A, Wasco S. Effectiveness of hotline, advocacy, counseling, and shelter services for victims of domestic violence: A statewide evaluation. J Interpers Violence. 2004;19(7):815-29. doi: 10.1177/0886260504265687. [PubMed: 15186538].

15. Abel T, McQueen D. The COVID-19 pandemic calls for spatial distancing and social closeness: not for social distancing!. Int J Public Health. 2020;65(3):231. doi: 10.1007/s00038-020-01366-7. [PubMed: 32239256]. [PubMed Central: PMC7111296].

16. Leslie E, Wilson R. Sheltering in place and domestic violence: Evidence from calls for service during COVID-19. J Public Econ. 2020;189:104241. doi: 10.1016/j.jpubeco.2020.104241. [PubMed: 32834179]. [PubMed Central: PMC7377795].

17. Bolhari J, Amiri T, Karimi Keisomi I, Mohseni Kabir M. Domestic violence prevention advocacy program: A pilot study in tehran urban area. IJPCP. 2018;24(2):124-35. doi: 10.32598/ijpcp.24.2.124.

18. Bao H. Anti-domestic violence little vaccine": A Wuhan-based feminist activist campaign during COVID-19. Interface. 2020;12(1):1-11.

19. Tower LE. Barriers in screening women for domestic violence: A survey of social workers, family practitioners, and obstetrician-gynecologists. J Fam Violence. 2006;21(4):245-57. doi: 10.1007/s10896-0069024-4.

20. Afdal A, Alizamar A, Ifdil I, Erlamsyah E, Taufik T. Guidance and counseling services for women victims of domestic violence. Atlantic Press; 2017. Available from: https://www.atlantis-press.com/proceedings/icset$17 / 25886649$.

21. Feder L, Dugan L. A test of the efficacy of court-mandated counseling for domestic violence offenders: The broward experiment. Justice $Q$. 2002;19(2):343-75.

22. Malik S, Naeem K. Impact of COVID-19 pandemic on women: Health, livelihoods \& domestic violence. 2020. Available from: http://hdl.handle.net/ $11540 / 11907$.

23. Yu R, Nevado-Holgado AJ, Molero Y, D'Onofrio BM, Larsson $\mathrm{H}$, Howard LM, et al. Mental disorders and intimate partner violence perpetrated by men towards women: A Swedish populationbased longitudinal study. PLoS Med. 2019;16(12). e1002995. doi: 10.1371/journal.pmed.1002995. [PubMed: 31846461]. [PubMed Central: PMC6917212].

24. Graham-Harrison EG, Smith H, Ford L. Lockdowns around the world bring rise in domestic violence. The Guardian; 2020. Available from: https://www.theguardian.com/society/2020/mar/28/lockdownsworld-rise-domestic-violence. 